\title{
Increased risk of pertussis in patients with asthma
}

\author{
Conrad R. Capili, BS ${ }^{a}$, Allison Hettinger, MD $^{b}$, Natalie Rigelman-Hedberg, MD ${ }^{\mathrm{a}}$, Lisa Fink, \\ PNP $^{\mathrm{b}}$, Thomas Boyce, MD ${ }^{\mathrm{b}}$, Brian Lahr, $\mathbf{M S}^{\mathrm{c}}$, and Young J. Juhn, MD, MPH ${ }^{\mathrm{b}}$ \\ aMayo Medical School, Mayo Clinic \\ ${ }^{b}$ Department of Pediatric and Adolescent Medicine, Mayo Clinic \\ 'Department of Health Sciences Research, Mayo Clinic
}

\begin{abstract}
Background-The recent pertussis outbreak in California highlights the effect of pertussis on public health. In 2004, a pertussis outbreak occurred in Olmsted County, Minnesota, despite a high vaccine uptake. This outbreak provided a natural experiment to assess the relationship between asthma and pertussis.
\end{abstract}

Objective-We sought to determine whether asthmatic subjects have a higher risk of pertussis than nonasthmatic subjects. Methods: We conducted a population-based case-control study. There were 223 pertussis cases identified by means of PCR in 2004 and 2005. We identified age- and sex-matched control subjects from 5537 patients with negative test results for pertussis. We conducted a comprehensive medical record review and applied predetermined criteria to ascertain asthma status. Conditional logistic regression was fit to assess the effect of asthma status on the risk of pertussis.

Results-Of the 223 subjects, 164 were eligible for the study, and 328 matched control subjects (1:2 matching) were enrolled. Of these 164 subjects, $50 \%$ were male, and $82 \%$ were white. The median age at the index date of pertussis was 14 years. Sixty-two (38\%) of the 164 cases had asthma before the index date of pertussis compared with 85 (26\%) of the 328 control subjects (odds ratio, $1.73 ; 95 \% \mathrm{CI}, 1.12-2.67 ; P=.013$ ). The population attributable risk percentage of asthma for risk of pertussis was $17 \%$.

Conclusions-Given the high prevalence of asthma and the ongoing risk of pertussis throughout the United States, consideration of defining asthmatic subjects as a target group for pertussis vaccination (eg, replacing decennial tetanus-diphtheria booster with tetanus, diphtheria, and acellular pertussis vaccine for adolescents and adults) should be given.

\section{Keywords}

Asthma; epidemiology; outbreak; Bordetella pertussis; risk; susceptibility; immunity; adolescents; children; population

Bordetella pertussis is a gram-negative bacterium that causes whooping cough, a serious respiratory tract infection affecting 800,000 to 3.3 million persons in the United States; it affects 50 million persons worldwide, causing 300,000 deaths annually. ${ }^{1-3}$ During the recent outbreak of pertussis in California in 2010, 9,143 pertussis cases were reported to the

(C) 2012 American Academy of Allergy, Asthma \& Immunology

Corresponding author: Young J. Juhn, MD, MPH, Division of Community Pediatric and Adolescent Medicine, Department of Pediatric and Adolescent Medicine, Mayo Clinic, 200 1st St SW, Rochester, MN 55905. juhn.young@ mayo.edu.

Disclosure of potential conflict of interest: The authors declare that they have no relevant conflicts of interest. 
California Department of Public Health. Among these cases, 9 nonimmunized infants died, most likely because of transmission from older children and adults in their families. ${ }^{4}$ This recent outbreak emphasizes that pertussis remains a major threat to public health in the United States. The number of reported pertussis cases in the United States increased from 1,010 cases in 1976 to 11,647 in $2003,18,957$ in 2004 , and 27,550 in $2010{ }^{5-9}$ During the 1980 s and 1990s, the proportionate increase was largest among infants, ${ }^{10}$ whereas during the 2000s, adolescents and adults were disproportionately affected. Among children 10 to 19 years old, the incidence increased from 5.5 per 100,000 in 2001 to 10.9 per 100,000 in 2003. These data suggest an increase in pertussis incidence, primarily because of the waning of humoral immunity over time.

Asthma is the most common chronic illness in childhood and is a major cause of morbidity in adults, affecting $4 \%$ to $17 \%$ of children and $7.3 \%$ to $10.1 \%$ of adults in the United States. ${ }^{11,12}$ At present, there are no signs of a decreasing trend in asthma prevalence; rather, the number of patients affected by asthma continues to increase in many parts of the world, affecting nearly 30 million Americans and 300 million persons globally. ${ }^{13,14}$ Despite this large proportion of populations affected by asthma, little is known regarding the risk of pertussis among subjects with asthma. Recently, we and other investigators reported increased risks of invasive or serious pneumococcal diseases among subjects with asthma. ${ }^{15,16}$ Subsequently updated recommendations by the Advisory Committee on Immunization Practices indicate that adults with asthma should receive a single dose of 23valent pneumococcal polysaccharide vaccine to prevent serious pneumococcal infections. Although this association can be only postulated in the context of the risk of other bacterial infections, such as pertussis, it is not currently known whether asthmatic subjects have an increased risk of pertussis compared with those without asthma. This question has important implications regarding the overall burden of pertussis on our health care system and community.

We conducted a population-based case-control study using a cohort of patients who resided in Olmsted County, Minnesota, and who had pertussis between January 1, 2004, and December 31, 2005, to determine the association between asthma and the risk of pertussis. The pertussis outbreak among this population provides an excellent opportunity for a natural experiment to examine the relationship between asthma and pertussis.

\section{METHODS}

The study was approved by the Institutional Review Boards at both Mayo Clinic and Olmsted County Medical Center. This is a retrospective, population-based case-control study of 164 eligible children and adults who had pertussis and 328 age- and sex-matched control subjects during the outbreak of $B$ pertussis infection in Olmsted County, Minnesota, between January 1, 2004, and December 31, 2005. The study compared a history of asthma between pertussis cases and matched control subjects.

\section{Study setting and population}

According to the 2000 Census, the population of Olmsted County, Minnesota, was 124,277 (90.3\% white compared with $89.4 \%$ white in Minnesota and $75.1 \%$ white in the United States). With the exception of a higher proportion of the working population employed in the health care industry, characteristics of Olmsted County populations were similar to those of the US white population. Medical care in Olmsted County is virtually self-contained within the community with a unified dossier-type medical record system for research among 2 medical centers containing all inpatient and outpatient data that have been indexed in an automated form since 1935 under the Rochester Epidemiology Project. ${ }^{17,18}$ This allows us 
to readily identify cases or events of interest and a community sample of study subjects representing the population of Olmsted County, Minnesota.

\section{Study design}

The study was designed as a population-based case-control study with an incidence-density case-control approach, permitting control subjects to become cases during the study period. ${ }^{19}$ We identified 1:2 age- and sex-matched control subjects who had a negative PCR test day closest to the index date of the corresponding pertussis cases.

\section{Study subjects: Case ascertainment}

A case was defined as isolation of $B$ pertussis by means of PCR from the upper respiratory tract among Olmsted County residents between January 1, 2004, and December 31, 2005. The sensitivity, specificity, positive predictive value, and negative predictive value of PCR to detect $B$ pertussis have been reported to be $93.5 \%, 97.1 \%, 84.3 \%$, and $99 \%$, respectively. ${ }^{20,21}$ We identified all reported cases through microbiology laboratory records from Mayo Clinic, the only laboratory in Olmsted County performing pertussis PCR tests. The exclusion criteria included (1) subjects who did not grant authorization for using medical records for research and (2) non-Olmsted County, Minnesota, residents.

\section{Selection of control subjects}

An age (birthday) - and sex-matched control group was randomly selected from a list of Olmsted County residents who had negative PCR results during the study period. Two control subjects were matched for each case with regard to sex, birthday (within 6 months for patients $<18$ years of age and within 1 year for patients $\geq 18$ years of age), and registration year within a range of 1 year. The exclusion criteria for control subjects were the same as those for cases.

\section{Exposure ascertainment (asthma status)}

Asthma status of all cases and control subjects was determined according to the specific predetermined criteria for asthma shown in Table I. These criteria have been extensively used in research for asthma epidemiology and were found to have high reliability. ${ }^{22-33} \mathrm{We}$ included both definite and probable asthma according to the criteria because most probable asthmatic subjects become definite asthmatic subjects over time. ${ }^{25,33}$ The incidence dates for all asthmatic subjects were determined; thus we were able to discern the temporal relationship between asthma status (exposure) and pertussis (outcome).

\section{Other variables}

Information on the following was also abstracted from the medical records: sociodemographic variables (age, sex, ethnicity, and educational status), asthma medications pertinent to the risk of pertussis at the time of the index date (inhaled and systemic corticosteroids), asthma severity at the index date based on medication use, history of other atopic conditions (allergic rhinitis, eczema, and hay fever), family history of atopic conditions, birth weight, gestational age, smoking status at the time of the index date (either active or passive exposure to tobacco smoke), pertussis vaccination status based on medical records during the study period (tetanus, diphtheria, and acellular pertussis vaccine for adolescents and adults [Tdap] did not significantly affect pertussis vaccination status of our study subjects because a booster dose of Tdap was not recommended by the Advisory Committee in Immunization Practices until June 2005 for adolescents and October 2005 for adults), and antibiotic use within 1 week before the index date of pertussis. 


\section{Data analysis}

Data were summarized with descriptive statistics, including counts and percentages for categorical variables or medians and interquartile ranges (IQRs) for continuous variables. Conditional logistic regression modeling with pertussis case status as the target of prediction was used to formally compare rates of risk factors between matched cases and control subjects and estimate the magnitude of individual associations by using odds ratios (ORs) and corresponding 95\% CIs. Given the study design (incidence-density case-control study), an OR approximates the rate ratio. In particular, we were interested in testing whether asthmatic subjects were at increased risk of pertussis infection. Multivariable modeling was also used to further evaluate the effect of asthma on the likelihood of being a pertussis case; controlling for any potential confounding effects from that demonstrated a significant or marginal association in the univariate modeling. Nominal factors with missing data were each categorized to include a category for unknown values, as well as observed levels, to include all subjects in the regression. ORs, $95 \% \mathrm{CIs}$, and $P$ values were reported from all univariate and multivariable models. Also, we estimated the population attributable risk percentage of asthma for pertussis infections. By using the formula established by Miettinen, ${ }^{34,35}$ the population attributable risk percentage was calculated as follows:

$$
\mathrm{P}(\mathrm{F} \mid \mathrm{D}) \times(\mathrm{OR}-1) / \mathrm{OR}
$$

where $P(F \mid D)$ is the prevalence of asthma among the pertussis cases of a population and $O R$ is the OR estimated from the conditional logistic regression model. By using similar methods, age-stratified analyses were performed to test for these associations within children and within adults. Certain asthma-related variables were assessed for an association with risk of pertussis among asthmatic subjects only. However, because the matching between pertussis cases and control subjects in this subset could not be retained, regular (unmatched) logistic regression was used. Statistical significance was tested at a 2 -sided $\alpha$ error of .05. All analyses were carried out with the SAS statistical software package (Version 9.2; SAS Institute, Inc, Cary, NC).

\section{RESULTS}

\section{Study subjects}

The characteristics of the subjects are summarized in Table II. ${ }^{32}$ Of the 223 reported pertussis cases, 164 were eligible, and 59 were excluded ( 47 were due to non-Olmsted County residency, and 12 were due to no research authorization). From the pool of eligible control subjects, 328 were matched (2:1) to cases within a median of 34 days from the index date of pertussis (ie, PCR test date for cases). Of the 164 cases, $50.0 \%$ were male, and $82 \%$ were white. The median age at the index date of pertussis was 13.9 years (IQR, 11.7-16.8 years), including $130(79.3 \%)$ cases younger than 18 years of age.

\section{Asthma and pertussis}

The summarized results for the association between asthma and pertussis are found in Tables III and IV. Sixty-two (37.8\%) of the 164 cases had asthma before the index date of pertussis compared with 85 (26\%) of the 328 control subjects (OR, 1.83; 95\% CI, 1.20-2.80; $P=.005)$. On the basis of this adjusted OR, the population attributable risk percentage of asthma for the risk of pertussis was $17 \%$ for all subjects. Of the 147 subjects who had asthma before the index date of pertussis, there were only 6 cases and 1 control subject who met the criteria for asthma within 90 days before the index date of pertussis. The association between asthma and risk of pertussis remained significant when excluding these subjects (OR, 1.78; 95\% CI, 1.16-2.73; $P=.008$ ). 
Because antibiotic use and a family history of asthma both approached statistical significance, we tested the association between asthma status and the risk of pertussis, adjusting for those 2 factors. A history of asthma before the index date was significantly associated with the risk of pertussis independent of antibiotic use and having a family history of asthma (OR, 1.73; 95\% CI, 1.12-2.67; $P=.013)$. Use of neither systemic corticosteroids (OR, $0.80 ; 95 \%$ CI, $0.29-2.20 ; P=.665)$ nor inhaled corticosteroids (OR, $0.79 ; 95 \% \mathrm{CI}, 0.37-1.69 ; P=.537)$ at the time of the index date was associated with an increased risk of pertussis (Table III). On the basis of the age-stratified analyses, the association between asthma and an increased risk of pertussis was only found in children and adolescents. Of the 174 subjects with asthma at any time, 147 (84.5\%) met the criteria for asthma before their index date of pertussis. A physician's diagnosis of asthma was not associated with an increased risk of pertussis (OR, 0.87; 95\% CI, 0.46-1.65; $P=.67$ ), and only about one third of subjects (37\% [64/174]) who met the criteria for asthma were given a diagnosis of asthma.

Although not statistically significant, a family history of asthma was associated with an increased risk of pertussis (OR, 1.46; 95\% CI, $0.94-2.25 ; P=.088)$. A family history of other atopic conditions was not associated with risk of pertussis (OR, 1.09; 95\% CI, 0.70$1.68 ; P=.710)$. Asthma severity at the index date based on medication use was not associated with the risk of pertussis.

\section{Other variables and pertussis}

With regard to pertussis vaccination status, 107 (65.2\%) cases were known to be fully immunized before the pertussis index date compared with 226 (68.9\%) control subjects $(P=$ 172). Of the 402 subjects who were immunized with pertussis vaccines at the time of the index date, $116(89.2 \%)$ of 130 asthmatic subjects were fully immunized with pertussis vaccines, whereas $217(79.8 \%)$ of 272 nonasthmatic subjects were fully immunized with pertussis vaccines $\left(P=.019, \chi^{2}\right.$ test $)$.

The risk of pertussis was not significantly associated with the presence of any high-risk comorbid conditions or household smoking exposure status at the index date. Also, the risk of pertussis was not associated with ethnicity. Educational level was not significantly associated with the risk of pertussis based on available data. Therefore these factors were not included in the models for adjustment of the main results.

\section{DISCUSSION}

Our study results show that asthma is associated with an increased risk of pertussis. The results were still significant after adjusting for the potential covariates and confounders. Our study findings are unlikely to be due to detection bias, which occurs when exposure (asthma status) affects detection of outcome (pertussis). For example, if detection bias significantly affects our study, we might expect to observe a stronger association between a physician's diagnosis of asthma and the risk of pertussis because of a higher likelihood of seeking medical evaluation by patients or caregivers or pertussis tests by clinicians among subjects with a physician's diagnosis of asthma compared with those without a physician's diagnosis of asthma. However, a physician's diagnosis of asthma was not associated with the risk of pertussis in our study (OR, $0.87 ; 95 \% \mathrm{CI}, 0.46-1.65 ; P=.67$ ) because only one third of subjects who met the criteria for asthma (37\%) were given a diagnosis of asthma. In addition, control subjects were identified from a cohort of Olmsted County residents who had been tested for pertussis and had negative results within a short period (1 month) of the index date of the corresponding cases. Thus detection bias because of differential outcome determination by exposure status (asthma) was minimized. Also, because of a concern about a potential misclassification of those with pertussis-induced respiratory symptoms as 
asthmatic subjects, we assessed the association between asthma and the risk of pertussis after excluding subjects who had asthma within 90 days before the index date, and the results remained significant. To our knowledge, there are no other population-based casecontrol studies that assessed the association between asthma and risk of pertussis to compare with our study. Previous descriptive studies have reported an association between asthma and pertussis. ${ }^{36,37}$ Our study findings are consistent with the recent reports on the association between asthma and other bacterial infections, such as invasive or serious pneumococcal diseases. ${ }^{15,16,38-41}$ Therefore our study results suggest a potential epidemiologic association between asthma and the risk of pertussis. However, the association between asthma and pertussis was only observed in the pediatric population in our study. Pertussis is generally considered a disease of early childhood, and previously vaccinated adults often present with mild and atypical symptoms, probably because of partial immunity. Thus pertussis is frequently unrecognized in adults, ${ }^{42}$ and adults without a diagnosis are often a significant source of infection for young children. ${ }^{4}$ Thus misclassification between cases and control subjects in adults is likely to be much higher than that in children. We postulate that this misclassification attenuates the association between pertussis and asthma in adults.

Plausible mechanisms for the increased risk of pertussis among asthmatic subjects include the potential adverse effects of inhaled or systemic corticosteroid therapies for asthma. Previous studies have demonstrated an increased risk of pneumonia and other morbidities in patients with chronic obstructive pulmonary disease treated with inhaled corticosteroids. ${ }^{43,44}$ However, our study revealed no significant associations between corticosteroid treatment (inhaled or systemic) and an increased risk of pertussis. This lack of the association between corticosteroids and infections in asthmatic subjects has been supported by the literature. ${ }^{45-47}$ Thus asthma medications are unlikely to account for the association between asthma and the risk of pertussis. Alternatively, asthmatic subjects have altered airway architecture (ie, early airway remodeling, increased mucous production, and impaired epithelial barrier function $)^{48,49}$ and impairment of innate and acquired immunity. ${ }^{46,50-57}$ These impairments could permit microbial organisms to penetrate the structurally compromised barrier of the respiratory tract and reduce the host's ability to clear pathologic organisms from airways. Alternatively, unvaccinated subjects are susceptible to pertussis, as previously reported. ${ }^{58}$ The proportion of subjects fully vaccinated among the pertussis cases in our study (69\%) appears to be within the range of what has been reported depending on age groups of subjects (50\% to $80 \%)^{2}$ Previous studies suggest that waning of humoral immunity over time might be an important factor in the cyclic pertussis outbreaks. ${ }^{59-61}$ For example, a previous study showed rapid waning of anti-pertussis toxin antibody levels after administering Tdap to subjects aged 11 to 65 years. ${ }^{61}$ In our study, compared with nonasthmatic subjects (80\%), a higher proportion of asthmatic subjects (90\%) were immunized with pertussis vaccine, and these results might suggest that asthma status could influence the durability of humoral immunity against pertussis. This interpretation is further supported by the fact that cases were predominantly adolescents who were fully immunized with pertussis vaccine (85\%). Indeed, according to our unpublished data, anti-pertussis toxin IgG levels appeared to be lower in children and adults with asthma (median, 2.5 enzymelinked immunoassay units [ELU]/mL; IQR, 2.5-10 ELU/mL; $\mathrm{n}=16$ ) compared with those seen in nonasthmatic subjects (median, $8 \mathrm{ELU} / \mathrm{mL}$;QR, 2.5-25 ELU/mL; $\mathrm{n}=14$ ), adjusting for the duration between the last pertussis vaccination and measurement of antibody levels, although the results did not reach statistical significance $(P=.063)$. In support of this finding, Prescott et al ${ }^{62}$ reported inverse correlations between IgE levels and diphtheria and tetanus-specific IgG titers in young children; moreover, failure to develop lymphoproliferative responses to tetanus toxoid was associated with higher serum IgE concentrations than seen in those with normal responses. Future studies concerning the mechanisms underlying the association between asthma and the risk of pertussis are needed. 
Specifically, the role of the reported impaired innate ${ }^{53,63-65}$ and adaptive immunity ${ }^{50,66-68}$ among atopic subjects in accounting for our study findings needs to be elucidated.

As implications of our study findings, according to the current vaccine policy, decennial tetanus-diphtheria $(\mathrm{Td})$ booster is recommended after preadolescent pertussis vaccinations at 11 to 12 years of age. Given the major outbreak of pertussis, the significant risk of pertussis among asthmatic subjects, and a significant number of Americans affected by asthma and the efficacy of the current acellular pertussis vaccine, consideration of replacing decennial $\mathrm{Td}$ booster with Tdap, which includes acellular pertussis vaccine, should be given in asthmatic subjects. Although the underlying mechanisms need to be elucidated, immune surveillance for $B$ pertussis in asthmatic subjects can be considered. Also, it might be an important public health and research issue to assess the effect of asthma on the risk of pertussis at a population level and monitor the trends over time.

The strengths of our study include epidemiologic advantages of a self-contained health care environment with a unified medical record system for research, which allows us to carry out a population-based case-control study. Also, ascertainment of asthma status was based on specific predetermined criteria, which have been extensively used in previous studies and with high reliability.

However, our study has inherent limitations as a retrospective study. Also, the residents of Olmsted County, Minnesota, were predominantly white; this might limit the external validity of our findings. However, at the cost of generalizability, this ethnically homogeneous population might minimize a confounding effect of ethnicity and socioeconomic status (and its related risk factors).

Our data abstractors were not blinded, which might introduce performance bias (observational bias). Although this is possible, ascertainment of asthma was based on specific predetermined criteria for asthma, which should minimize bias.

In conclusion, given the major outbreak of pertussis in the United States, the significant risk of pertussis among asthmatic subjects, and a significant number of Americans affected by asthma, consideration of replacing decennial Td booster with Tdap, which includes acellular pertussis vaccine, should be given in subjects with asthma. Immune surveillance for $B$ pertussis in asthmatic subjects as a selective risk group should be considered as well.

\section{Acknowledgments}

Supported by the Clinician Scholarly Award from the Mayo Foundation made possible by the Rochester Epidemiology Project (R01-AR30582) from the National Institute of Arthritis and Musculoskeletal and Skin Diseases.

We thank the staff of the Pediatric Asthma Epidemiology Research Unit who made this study possible. We also thank Elizabeth Krusemark for administrative assistance.

\section{Abbreviations used}

$\begin{array}{ll}\text { ELU } & \text { Enzyme-linked immunoassay units } \\ \text { IQR } & \text { Interquartile range } \\ \text { OR } & \text { Odds ratio } \\ \text { Td } & \text { Tetanus-diphtheria } \\ \text { Tdap } & \text { Tetanus, diphtheria, and acellular pertussis vaccine for adolescents and adults }\end{array}$




\section{References}

1. Black S. Epidemiology of pertussis. Pediatr Infect Dis J. 1997; 16(suppl):S85-9. [PubMed: 9109162]

2. Guris D, Strebel PM, Bardenheier B, Brennan M, Tachdjian R, Finch E, et al. Changing epidemiology of pertussis in the United States: increasing reported incidence among adolescents and adults, 1990-1996. Clin Infect Dis. 1999; 28:1230-7. [PubMed: 10451158]

3. Tanaka M, Vitek C, Pascual F, Bisgard KM, Tate JE, Murphy TV. Trends in pertussis among infants in the United States, 1980-98. JAMA. 2003; 290:2968-75. [PubMed: 14665658]

4. Pertussis Report. The California Department of Public Health; 2010. Available at: http://www.cdph.ca.gov/programs/immunize/Documents/PertussisReport2010-10-26.pdf

5. Centers for Disease Control and Prevention. Summary of notifiable diseases, United States, 2003. MMWR Morb Mortal Wkly Rep. 2003; 52:1-85.

6. Pichichero M, Blatter M, Kennedy W, Hedrick J, Descamps D, Firiedland L. Acellular pertussis vaccine booster combined with diphtheria and tetanus toxoids for adolescents. Pediatrics. 2006; 117:1084-93. [PubMed: 16585302]

7. Pichichero ME, Rennels MB, Edwards KM, Blatter MM, Marshall GS, Bologa M, et al. Combined tetanus, diphtheria, and 5-component pertussis vaccine for use in adolescents and adults. JAMA. 2005; 293:3003-11. [PubMed: 15933223]

8. Centers for Disease Control and Prevention. Notifiable diseases/deaths in selected cites weekly information. MMWR Morb Mortal Wkly Rep. 2004; 53:1213-21.

9. Centers for Disease Control and Prevention. [Accessed September 30, 2011.] Pertussis fast facts. 2011. Available at: http://www.cdc.gov/pertussis/fast-facts.html

10. Bisgard KM, Pascual FB, Ehresmann KR, Miller CA, Cianfrini C, Jennings CE, et al. Infant pertussis: who was the source? Pediatr Infect Dis J. 2004; 23:985-9. [PubMed: 15545851]

11. Lethbridge-Cejku, M.; Vickerie, J. Summary of health statistics for US adults: national health interview survey, 2003. Atlanta: National Center for Health Statistics; 2005.

12. Forecasted state-specific estimates of self-reported asthma prevalence -United States, 1998. MMWR Morb Mortal Wkly Rep. 1998; 47:1022-5. [PubMed: 9853939]

13. World Health Organization. [Accessed October 26, 2006.] Fact sheet for asthma. 2005. Fact sheet for asthma N307. Available at: http://www.who.int/int/mediacentre/factsheets/fs307/en/

14. Anandan C, Nurmatov U, van Schayck OC, Sheikh A. Is the prevalence of asthma declining? Systematic review of epidemiological studies. Allergy. 2010; 65:152-67. [PubMed: 19912154]

15. Talbot T, Hartert TV, Arbogast PG, Mitchel E, Schaffner K, Craig AS, et al. Asthma as a risk factor for invasive pneumococcal disease. N Engl J Med. 2005; 352:2082-90. [PubMed: 15901861]

16. Juhn YJ, Kita H, Yawn BP, Boyce TG, Yoo KH, McGree ME, et al. Increased risk of serious pneumococcal disease in patients with asthma. J Allergy Clin Immunol. 2008; 122:719-23. [PubMed: 18790525]

17. Melton L. History of the Rochester Epidemiology Project. Mayo Clin Proc. 1996; 71:266-74. [PubMed: 8594285]

18. St Sauver JL, Grossardt BR, Yawn BP, Melton LJ, Rocca WA. Use of a medical records linkage system to enumerate a dynamic population over time: the Rochester Epidemiology Project. Am J Epidemiol. 2011; 173:1059-68. [PubMed: 21430193]

19. Hogue CJ, Gaylor DW, Schulz KF. Estimators of relative risk for case-control studies. Am J Epidemiol. 1983; 118:396-407. [PubMed: 6613982]

20. Loeffelholz MJ, Thompson CJ, Long KS, Gilchrist MJ. Detection of Bordetella holmesii using Bordetella pertussis IS481 PCR assay. J Clin Microbiol. 2000; 38:467. [PubMed: 10681208]

21. Loeffelholz MJ, Thompson CJ, Long KS, Gilchrist MJ. Comparison of PCR, culture, and direct fluorescent-antibody testing for detection of Bordetella pertussis. J Clin Microbiol. 1999; 37:2872-6. [PubMed: 10449467]

22. Beard CM, Yunginger JW, Reed CE, O'Connell EJ, Silverstein MD. Interobserver variability in medical record review: an epidemiological study of asthma. J Clin Epidemiol. 1992; 45:1013-20. [PubMed: 1432015] 
23. Silverstein M, Reed CE, O'Connell EJ, Melton L, O'Fallon W, Yunginger JW. Long-term survival of a cohort of community residents with asthma. N Engl J Med. 1994; 331:1537-41. [PubMed: 7969322]

24. Hunt W, Silverstein M, Reed CE, O'Connell EJ, O'Fallon W, Yunginger JW. Accuracy of the death certificate in a population-based study of asthmatic patients. JAMA. 1993; 269:1947-52. [PubMed: 8464126]

25. Yunginger J, Reed CE, O'Connell EJ, Melton J, O'Fallon WM, Silverstein MD. A communitybased study of the epidemiology of asthma: incidence rates, 1964-1983. Am Rev Respir Dis. 1992; 146:888-94. [PubMed: 1416415]

26. Beard M, Yunginger JW, Reed CE, O’Connell EJ, Silverstein MD. Interobserver variability in medical record review: an epidemiological study of asthma. J Clin Epidemiol. 1992; 45:1013-20. [PubMed: 1432015]

27. Bauer B, Reed CE, Yunginger JW, Wollan P, Silverstein MD. Incidence and Outcomes of Asthma in the Elderly: a population-based study in Rochester, MN. Chest. 1997; 111:303-10. [PubMed: 9041973]

28. Silverstein MD, Yunginger JW, Reed CE, Petterson T, Zimmerman D, Li JT, et al. Attained adult height after childhood asthma: effect of glucocorticoid therapy. J Allerg Clin Immunol. 1997; 99:466-74.

29. Juhn YJ, Sauver JS, Katusic S, Vargas D, Weaver A, Yunginger J. The influence of neighborhood environment on the incidence of childhood asthma: a multilevel approach. Soc Sci Med. 2005; 60:2453-64. [PubMed: 15814171]

30. Juhn Y, Weaver A, Katusic S, Yunginger J. Mode of delivery at birth and development of asthma: a population-based cohort study. J Allergy Clin Immunol. 2005; 116:510-6. [PubMed: 16159617]

31. Juhn YJ, Kita H, Lee LA, Smith RW, Bagniewski SM, Weaver AL, et al. Childhood asthma and human leukocyte antigen type. Tissue Antigens. 2007; 69:38-46. [PubMed: 17212706]

32. Yawn B, Yunginger JW, Wollan P, Reed CE, Silverstein M, Harris A. Allergic rhinitis in Rochester, Minnesota residents with asthma: Frequency and impact on health care charges. J Allergy Clin Immunol. 1999; 103:54-9. [PubMed: 9893185]

33. Juhn YJ, Kita H, Lee LA, Swanson RJ, Smith R, Bagniewski SM, et al. Childhood asthma andmeasles vaccine response. Ann Allergy Asthma Immunol. 2006; 97:469-76. [PubMed: 17069101]

34. Miettinen OS. Proportion of disease caused or prevented by a given exposure, trait or intervention. Am J Epidemiol. 1974; 99:325-32. [PubMed: 4825599]

35. Koepsell, TD.; Weiss, NS. Epidemiologic methods studying the occurrence of illness. Oxford: Oxford University; 2003.

36. De Serres G, Shadmani R, Duval B, Boulianne N, Dery P, Douville Fradet M, et al. Morbidity of pertussis in adolescents and adults. J Infect Dis. 2000; 182:174-9. [PubMed: 10882595]

37. Kendirli S. Potential association between allergic diseases and pertussis infection in schoolchildren: results of two cross-sectional studies seven years apart. Allergol Immunopathol. 2009; 37:21-5.

38. Almirall J, Bolibar I, Serra-Prat M, Roig J, Hospital I, Carandell E, et al. New evidence of risk factors for community-acquired pneumonia: a population-based study. Eur Respir J. 2008; 31:1274-84. [PubMed: 18216057]

39. Klemets P, Lyytikainen O, Ruutu P, Ollgren J, Kaijalainen T, Leinonen M, et al. Risk of invasive pneumococcal infections among working age adults with asthma. Thorax. 2010; 65:698-702. [PubMed: 20685743]

40. Flory JH, Joffe M, Fishman NO, Edelstein PH, Metlay JP. Socioeconomic risk factors for bacteraemic pneumococcal pneumonia in adults. Epidemiol Infect. 2009; 137:717-26. [PubMed: 18925988]

41. Santos JCH, Zhang L, Menegatti PK, Guasselli CS, Celso Filho CM, Maito LR, et al. Pneumonia during the first 2 years of life and asthma in preschool-age children. Pediatr Int. 2011; 53:576-80. [PubMed: 21342353]

42. American Academy of Pediatrics. Red book 2009. Elk Grove Village (IL): American Academy of Pediatrics; 2009. 
43. Singh S, Loke YK. Risk of pneumonia associated with long-term use of inhaled corticosteroids in chronic obstructive pulmonary disease: a critical review and update. Curr Opin Pulm Med. 2010; 16:118-22. [PubMed: 19926996]

44. Singh S, Amin AV, Loke YK. Long-term use of inhaled corticosteroids and the risk of pneumonia in chronic obstructive pulmonary disease: a meta-analysis. Arch Intern Med. 2009; 169:219-29. [PubMed: 19204211]

45. Masten B, McWilliams B, Lipscomb M, Archibeque T, Qualls C, Kelly HW, et al. Immune response to hepatitis B vaccine in asthmatic children. Pediatr Pulmonol. 2003; 36:522-8. [PubMed: 14618645]

46. Lahood N, Emerson SS, Kumar P, Sorensen RU. Antibody levels and response to pneumococcal vaccine in steroid-dependent asthma. Ann Allergy. 1993; 70:289-94. [PubMed: 8466093]

47. O’Byrne PM, Pedersen S, Carlsson LG, Radner F, Thoren A, Peterson S, et al. Risks of pneumonia in patients with asthma taking inhaled corticosteroids. Am J Respir Crit Care Med. 2011; 183:58995. [PubMed: 20889908]

48. Murphy D, O’Byrne P. Recent advances in the pathophysiology of asthma. Chest. 2010; 137:1417-26. [PubMed: 20525652]

49. Holgate S. Epithelium dysfunction in asthma. J Allergy Clin Immunol. 2007; 120:1233-44. [PubMed: 18073119]

50. Grove DI, Burston TO, Wellby ML, Ford RM, Forbes IJ. Humoral and cellular immunity in asthma. J Allergy Clin Immunol. 1975; 55:152-63. [PubMed: 1089697]

51. Fahy JV, Corry DB, Boushey HA. Airway inflammation and remodeling in asthma. Curr Opin Pulm Med. 2000; 6:15-20. [PubMed: 10608420]

52. Wark PAB, Johnston SL, Bucchieri F, Powell R, Puddicombe S, Laza-Stanca V, et al. Asthmatic bronchial epithelial cells have a deficient innate immune response to infection with rhinovirus. $\mathbf{J}$ Exp Med. 2005; 201:937-47. [PubMed: 15781584]

53. Contoli M, Message SD, Laza-Stanca V, Edwards MR, Wark PA, Bartlett MW, et al. Role of deficient type III interferon-lambda production in asthma exacerbations. Nat Med. 2006; 12:10236. [PubMed: 16906156]

54. Fischer JE, Johnson JE, Kuli-Zade RK, Johnson TR, Aung S, Parker RA, et al. Overexpression of interleukin-4 delays virus clearance in mice infected with respiratory syncytial virus. J Virol. 1997; 71:8672-7. [PubMed: 9343225]

55. Kincy-Cain T, Clements JD, Bost KL. Endogenous and exogenous interleukin-12 augment the protective immune response in mice orally challenged with Salmonella dublin. Infect Immun. 1997; 64:1437-40. [PubMed: 8606114]

56. Chapin D, Duffy L, Atkinson T, Lai J. Clearance of Mycoplasma pneumoniae is impaired in mice with established allergic airway inflammation. J Allergy Clin Immunol. 2007; 119(suppl):S132.

57. Jung JA, Kita H, Dhillon R, Jacobson RM, Nahm MH, Park M, et al. Influence of asthma status on serotype specific antibody pneumococcal antibody levels. Post-grad Med. 2010; 122:116-24.

58. Centers for Disease Control and Prevention. Pertussis-United States, 2001-2003. MMWR Morb Mortal Wkly Rep. 2005; 54:1283-6. [PubMed: 16371944]

59. Edwards KM. Overview of pertussis: focus on epidemiology, sources of infection, and long term protection after infant vaccination. Pediatr Infect Dis J. 2005; 24(suppl):S104-8. [PubMed: 15931137]

60. Hellenbrand W, Beier D, Jensen E, Littmann M, Meyer C, Oppermann H, et al. The epidemiology of pertussis in Germany: past and present. BMC Infect Dis. 2009; 9:22. [PubMed: 19243604]

61. Krassilnikova S, Mende C, Craig T. Changes in anti-pertussis titers in adults following pertussis vaccine. J Allergy Clin Immunol. 2006; 117(suppl):S209.

62. Prescott SL, Sly PD, Holt PG. Raised serum IgE associated with reduced responsiveness to DPT vaccination during infancy. Lancet. 1998; 351:1489. [PubMed: 9605810]

63. Marenholz I, Kerscher T, Bauerfeind A, Esparza-Gordillo J, Nickel R, Keil T. An interaction between filaggrin mutations and early food sensitization improves the prediction of childhood asthma. J Allergy Clin Immunol. 2009; 123:911-6. [PubMed: 19348926] 
64. Weidinger S, O’Sullivan M, Illig T, Baurecht H, Depner M, Rodriguez E, et al. Filaggrin mutations, atopic eczema, hay fever, and asthma in children. J Allergy Clin Immunol. 2008; 121:1203-1209.e1. [PubMed: 18396323]

65. Wark PA, Johnston SL, Bucchieri F, Powell R, Puddicombe S, Laza-Stanca V, et al. Asthmatic bronchial epithelial cells have a deficient innate immune response to infection with rhinovirus. $\mathrm{J}$ Exp Med. 2005; 201:937-47. [PubMed: 15781584]

66. Strannegard IL, Lindholm L, Strannegard O. T lymphocytes in atopic children. International Arch Allergy Appl Immunol. 1976; 50:684-92.

67. Grove DIRJ, Forbes IJ. Humoral and cellular immunity in atopic eczema. Br J Dermatol. 1975; 92:611-8. [PubMed: 1101939]

68. Schneider LC, Weinberg A, Boguniewicz M, Zaccaro D, Taylor P, Borras-Coughlin I, et al. Abnormal immune response to varicella vaccine in subjects with atopic dermatitis compared to non-atopic controls. J Allergy Clin Immunol. 2008; 121(suppl 1):S272-3. 


\section{Clinical implications}

Asthmatic subjects are at increased risk for pertussis infection. Targeting asthmatic subjects for pertussis vaccination as a selective high-risk group might be appropriate. 


\section{TABLE I}

\section{Definition of asthma}

Patients were considered to have definite asthma if a physician had made a diagnosis of asthma, if each of the following 3 conditions were present, or both, and they were considered to have probable asthma if only the first 2 conditions were present:

1 history of cough, dyspnea, and/or wheezing OR history of cough and/or dyspnea plus wheezing on examination;

2 substantial variability in symptoms from time to time or periods of weeks or more when symptoms were absent; and

3 two or more of the following:

- $\quad$ sleep disturbance caused by nocturnal cough and wheeze;

- $\quad$ nonsmoking status ( $\geq 14$ y old);

- $\quad$ nasal polyps;

- $\quad$ blood eosinophilia $>300 / \mu \mathrm{L}$;

- $\quad$ positive wheal-and-flare skin test results OR increased serum IgE levels;

- $\quad$ history of hay fever or infantile eczema OR cough, dyspnea, and wheezing regularly on exposure to an antigen;

- $\quad$ pulmonary function tests showing one $\mathrm{FEV}_{1}$ or forced vital capacity measurement of greater than $70 \%$ of predicted value and another with at least $20 \%$ improvement to an $\mathrm{FEV}_{1}$ of greater than $70 \%$ of predicted value OR a methacholine challenge test showing a $20 \%$ or greater decrease in $\mathrm{FEV}_{1}$; or

- a favorable clinical response to a bronchodilator. 


\section{TABLE II}

Sociodemographic and clinical characteristics of patients with pertussis and their matched control subjects

\begin{tabular}{|c|c|c|c|}
\hline & Control subjects $(\mathrm{n}=\mathbf{3 2 8})$ & Cases $(n=164)$ & OR $(95 \% \mathrm{CI}), P$ value \\
\hline \multicolumn{4}{|l|}{ Age at case's index date (y) } \\
\hline Median (IQR) & $13.9(11.7-16.9)$ & $13.9(11.6-16.6)$ & - \\
\hline \multicolumn{4}{|l|}{ Age group, no. $(\%)$} \\
\hline$<18$ y & $261(79.6)$ & $130(79.3)$ & - \\
\hline$\geq 18$ y & $67(20.4)$ & $34(20.7)$ & - \\
\hline \multicolumn{4}{|l|}{ Sex, no. $(\%)$} \\
\hline Male & $164(50)$ & $82(50)$ & - \\
\hline Female & $164(50)$ & $82(50)$ & - \\
\hline Ethnicity, no. (\%) & & & See results below \\
\hline Hispanic/Latino & $4(1.2)$ & $1(0.6)$ & \\
\hline American Indian/Alaska Native & $1(0.3)$ & 0 & \\
\hline Asian & $4(1.2)$ & 0 & \\
\hline Native Hawaiian/other Pacific Islander & 0 & $2(1.2)$ & \\
\hline Black/African American & $4(1.2)$ & 0 & \\
\hline White & $255(77.7)$ & $134(81.7)$ & \\
\hline Unknown & $60(18.3)$ & $27(16.5)$ & \\
\hline \multicolumn{4}{|l|}{ Ethnicity, no. (\%) } \\
\hline Nonwhites & $13(3.9)$ & $3(1.8)$ & Referent \\
\hline Whites & $255(78)$ & $134(82)$ & $2.36(0.65-6.57), .193$ \\
\hline Unknown & $60(18.3)$ & $27(16.5)$ & $1.98(0.52-7.60), .321$ \\
\hline \multicolumn{4}{|l|}{ Educational status, ${ }^{*}$ no. $(\%)$} \\
\hline High school or less & $20(6.1)$ & $13(7.9)$ & Referent \\
\hline Some college & $33(10.1)$ & $20(12.2)$ & $0.89(0.35-2.29), .812$ \\
\hline College graduate & $23(7.0)$ & $13(7.9)$ & $0.87(0.31-2.47), .790$ \\
\hline Graduate degree or greater & $20(6.1)$ & $5(3.0)$ & $0.39(0.11-1.36), .139$ \\
\hline Unknown & $232(70.7)$ & $113(68.9)$ & $0.62(0.23-1.63), .331$ \\
\hline \multicolumn{4}{|l|}{ Family history of asthma, no. (\%) } \\
\hline No & $197(60.1)$ & $87(53.0)$ & Referent \\
\hline Yes & $94(28.7)$ & $60(36.6)$ & $1.47(0.96-2.25), .074$ \\
\hline Unknown & $37(11.3)$ & $17(10.4)$ & $1.05(0.51-2.17), .904$ \\
\hline \multicolumn{4}{|c|}{ Up-to-date status on pertussis vaccination, no. (\%) } \\
\hline Not up to date & $42(12.8)$ & $27(16.5)$ & Referent \\
\hline Up to date & $226(68.9)$ & $107(65.2)$ & $0.63(0.32-1.22), .172$ \\
\hline Unknown & $60(18.3)$ & $30(18.3)$ & $0.81(0.33-2.02), .656$ \\
\hline \multicolumn{4}{|l|}{ Antibiotic use before index date, no. (\%) } \\
\hline No & $318(97.0)$ & $153(93.3)$ & Referent \\
\hline Yes & $10(3.0)$ & $11(6.7)$ & $2.20(0.93-5.18), .071$ \\
\hline
\end{tabular}




\begin{tabular}{|c|c|c|c|}
\hline & Control subjects $(n=328)$ & Cases $(n=164)$ & OR $(95 \% \mathrm{CI}), P$ value \\
\hline \multicolumn{4}{|l|}{ Household smoking exposure at index date, no. (\%) } \\
\hline No & $81(24.7)$ & $42(25.6)$ & Referent \\
\hline Yes & $53(16.2)$ & $29(17.7)$ & $1.26(0.58-2.71), .56$ \\
\hline Unknown & $194(59.1)$ & $93(56.7)$ & - \\
\hline Comorbid conditions, ${ }^{\dagger}$ no. (\%) & & & See results below \\
\hline Sickle cell disease & $1(0.3)$ & 0 & \\
\hline Primary immune deficiency & 0 & $2(1.2)$ & \\
\hline Cardiac disease & $7(2.1)$ & $3(1.8)$ & \\
\hline Chronic pulmonary disease & $1(0.3)$ & $1(0.6)$ & \\
\hline Neurosurgical trauma/procedure & $4(1.2)$ & 0 & \\
\hline Chronic renal insufficiency & 0 & $2(1.2)$ & \\
\hline Immunosuppressive therapy $\frac{\hbar}{t}$ & $1(0.3)$ & 0 & \\
\hline Diabetes mellitus, type I & $2(0.6)$ & $2(1.2)$ & \\
\hline Diabetes mellitus, type II & $3(0.9)$ & 0 & \\
\hline Alcohol abuse & $2(0.6)$ & 0 & \\
\hline COPD in absence of asthma & $2(0.6)$ & 0 & \\
\hline Rheumatoid arthritis & $3(0.9)$ & 0 & \\
\hline Inflammatory bowel disease & $2(0.6)$ & $3(1.8)$ & \\
\hline Hepatic disease & $1(0.3)$ & 0 & \\
\hline $\begin{array}{l}\text { Long-term corticosteroid use/high-dose steroid use at index } \\
\text { date }^{\S}\end{array}$ & $2(0.6)$ & $1(0.6)$ & \\
\hline \multicolumn{4}{|l|}{ Comorbidities before index date, no. (\%) } \\
\hline None & $318(97.0)$ & $156(95.1)$ & Referent \\
\hline Any & $9(2.7)$ & $8(4.9)$ & $2.44(0.70-8.57), .163$ \\
\hline
\end{tabular}

$C O P D$, Chronic obstructive lung disease.

*

For children, parents' educational status was used.

${ }^{\dagger}$ Comorbid conditions were not mutually exclusive because subjects could have more than 1 condition.

tDefined as immunosuppressive drug intake for malignant neoplasms, leukemias, lymphomas, Hodgkin disease, and solid organ transplantation before the index date.

$\S_{\text {Defined by the definition of the Red Book. }}{ }^{32}$ 


\section{TABLE III}

Association between asthma and its related factors and risk of pertussis

\begin{tabular}{|c|c|c|c|}
\hline & Control subjects $(n=328)$ & Cases $(n=164)$ & OR $(95 \% \mathrm{CI}), P$ value \\
\hline \multicolumn{4}{|l|}{ History of asthma before index date, ${ }^{*}$ no. $(\%)$} \\
\hline No & $243(74.1)$ & $102(62.2)$ & Referent \\
\hline Yes & $85(25)$ & $62(37.8)$ & $1.83(1.20-2.80), .005$ \\
\hline Subgroup analyses of asthmatic subjects ${ }^{\dagger}$ & $\mathrm{n}=85$ & $\mathrm{n}=62$ & Unmatched analyses \\
\hline \multicolumn{4}{|l|}{ Asthma severity at index date, ${ }^{\dagger}$ no. $(\%)$} \\
\hline Inactive asthma or remission & $28(32.9)$ & $26(41.9)$ & Referent \\
\hline Mild intermittent asthma & $30(35.3)$ & $21(33.9)$ & $0.75(0.35-1.63), .473$ \\
\hline Persistent asthma & $27(31.8)$ & $15(24.2)$ & $0.60(0.26-1.37), .223$ \\
\hline \multicolumn{4}{|c|}{ Inhaled corticosteroid treatment at index date, ${ }^{\dagger}$ no. $(\%)$} \\
\hline No & $62(72.9)$ & $48(77.4)$ & Referent \\
\hline Yes & $23(27.1)$ & $14(22.6)$ & $0.79(0.37-1.69), .537$ \\
\hline \multicolumn{4}{|c|}{ Burst course of systemic steroid in 90 days before index date ${ }^{\dagger}$} \\
\hline No & $76(89.4)$ & $54(87.1)$ & Referent \\
\hline Yes & $9(10.6)$ & $8(12.9)$ & $1.25(0.45-3.45), .665$ \\
\hline
\end{tabular}

The results were based on matched analyses.

${ }^{\dagger}$ The results were analyzed by using a subgroup of asthmatic subjects $(n=147)$ only based on unmatched analyses.

*Inactive asthma or remission of asthma was defined by no symptoms of asthma, no use of asthma medications, no clinic visits, and no emergency department visits or hospitalizations for 3 years. 


\section{TABLE IV}

Association between risk of pertussis and a history of asthma based on matched analysis adjusting for covariates

\begin{tabular}{|c|c|c|c|}
\hline Variables & All subjects $(\mathrm{n}=\underset{\text { value }}{492),} \mathrm{OR}(95 \% \mathrm{CI}), P$ & Children $(\mathrm{n}=\mathbf{3 9 1}), \mathrm{OR}(95 \% \mathrm{CI}), P$ & Adults $(\mathrm{n}=\underset{\text { value }}{101), \mathrm{OR}}(95 \% \mathrm{CI}), P$ \\
\hline \multicolumn{4}{|c|}{ Asthma before index date } \\
\hline Unadjusted & $1.83(1.20-2.80), .005$ & $2.01(1.26-3.20), .003$ & $1.10(0.38-3.22), .855$ \\
\hline Adjusted* & $1.73(1.12-2.67), .013$ & $1.92(1.20-3.09), .007$ & $1.14(0.37-3.55), .820$ \\
\hline
\end{tabular}

* ORs were calculated after adjusting for a family history of asthma and antibiotic use within 1 week before the index date of pertussis; both unadjusted and adjusted results have controlled for age and sex in the matched design. 